\title{
CORRECTION
}

\section{Correction: Argatroban therapy for heparin-induced thrombocytopenia in ICU patients with multiple organ dysfunction syndrome: a retrospective study}

\author{
Bernd Sauge|*1, Veit Phillip', Georg Moessmer², Roland M Schmid' and Wolfgang Huber ${ }^{1}$ \\ See related research by Saugel et al., http://ccforum.com/content/14/3/R90
}

\section{Correction}

After publication of their article [1], the authors found several errors as listed below;

- In the first paragraph of the introduction; "In patients with recent heparin exposure within the previous 100 days, clinically significant HIT antibodies may still circulate and can therefore cause an abrupt decrease in platelet count with restarting of heparin treatment [8]", reference 21 should be cited here instead and reference 8 should be deleted entirely from the manuscript and reference list.

- Also, in the first paragraph of the introduction, the following sentence "If platelet count decreases to $\geq 50 \%$ or thrombosis occurs between day 5 and 14 of heparin therapy, or both, HIT should be suspected [7]" should be changed to read "If platelet count decreases by $\geq 50 \%$ or thrombosis occurs between day 5 and 14 of heparin therapy, or both, HIT should be suspected [7]."

- The following reference was erroneously deleted from the manuscript:

"Kodityal S, Nguyen PH, Kodityal A, Sherer J, Hursting MJ, Rice L: Argatroban for suspected heparininduced thrombocytopenia: contemporary experience at a large teaching hospital. I Intensive Care Med 2006, 21(2):86-92". This reference should therefore be cited in the following text (in addition to the given references);

Introduction, First paragraph: “...leading to limb amputations in $10 \%$ to $20 \%$ and to death in $20 \%$ to $30 \%$ of cases [3-6]."

Discussion, first paragraph: "However, the diagnosis of HIT should be based on clinical considerations and

*Correspondence: bernd.saugel@|rz.tu-muenchen.de

'II. Medizinische Klinik, Klinikum rechts der Isar der Technischen Universität München, Ismaningerstr. 22, 81675 München, Germany

Full list of author information is available at the end of the article treatment should not be delayed, pending laboratory confirmation $[3,7]$.

On suspicion of HIT, all sources of heparin should be eliminated and an alternative anticoagulant must be initiated [7]."

Discussion, third paragraph: "Lepirudin is renally cleared and associated with an increased elimination half-life and bleeding risk in renal failure [27]."

- The following sentence under the Materials and Methods section in the second paragraph should be changed from "HIT was defined as a decrease in platelet count to $>150 \times 10^{9} / \mathrm{L}$ or..." to read "HIT was defined as a decrease in platelet count to $<150 \times 10^{9} / \mathrm{L}$ or..."

- The following sentence under the Discussion section in the seventh paragraph should be changed from "All patients had developed thrombocytopenia after heparin exposure and had argatroban treatment initiated for suspected HIT whether the diagnosis was ultimately confirmed" to read "In all patients treated with argatroban, HIT was suspected because of a decrease in platelet count following heparin exposure.."

\section{Competing interests}

The authors declare that they have no competing interests.

\section{Author details}

${ }^{1}$ II. Medizinische Klinik, Klinikum rechts der Isar der Technischen Universität München, Ismaningerstr. 22, 81675 München, Germany. ${ }^{2}$ Institut für klinische Chemie und Pathobiochemie, Klinikum rechts der Isar der Technischen Universität München, Ismaningerstr. 22, 81675 München, Germany.

Published: 22 March 2012

\section{Reference}

1. Saugel B, Phillip V, Moessmer G, Schmid RM, Huber W: Argatroban therapy for heparin-induced thrombocytopenia in ICU patients with multiple organ dysfunction syndrome: a retrospective study. Critical Care 2010, 14:R90.

\section{doi:10.1186/cc11251}

Cite this article as: Saugel B, et al:: Correction: Argatroban therapy for heparin-induced thrombocytopenia in ICU patients with multiple organ dysfunction syndrome: a retrospective study. Critical Care 2012, 16:415. 